\title{
Towards a taxonomy for public communication of science activities
}

\section{María del Carmen Sánchez-Mora}

\begin{abstract}
As a result of the large number of media used and a variety of objectives pursued by the various Public Communication of Science (PCS) activities, their evaluation turns into a daunting task. Therefore, a general taxonomy for all the approaches used by PCS could be helpful in order to differentiate their effects and to measure their results. A general format is proposed for a fast and easy evaluation of PCS efforts and to share a common language with all science communicators, who need to easily compare the results of this growing activity.
\end{abstract}

Keywords

Popularization of science and technology; Science and media; Science communication: theory and models

Over the past 20 years, a number of institutions have carried out very diverse activities of public communication of science (PCS) ${ }^{1}$ with an array of purposes such as entertaining, informing, enabling, educating, raising awareness, empowering or creating a social scientific and technological knowledge, which can eventually lead to the creation of what is referred to as scientific culture. ${ }^{2}$

In order to analyse and evaluate public communication of science (PCS) in the long term - given the variety and complexity of the events it implies - the community of the popularisers who practice it should start using a shared taxonomy and terminology, as otherwise - owing to the lack of a common classification of their actions - the shared goals achieved by their work may become confused, difficult to evaluate and even hardly comparable.

The taxonomy of the different PSC media and their scopes may also enable institutions engaged in such work to consider the specific weight of their activities,

\footnotetext{
${ }^{1}$ By PCS activities we mean the multi, inter and transdisciplinary field of knowledge that puts together information from various domains such as natural science, exact sciences, medicine, technologies, engineering and, recently, social and human sciences, as well as the management of the various media and the knowledge of the various audiences. With such term, we intend to group all the approaches used in science popularisation and communication.

${ }^{2}$ Vaccarezza [2009] defines it as the interrelation between creators of scientific knowledge and other social groups, all of them as participants in the evolution of culture, producing meanings whose origins and justifications come from different practices, interests, regulatory codes and power relations in a constant interaction.
} 
and eventually to make decisions that involve diversification in terms of approaches, audiences and media to exercise PCS, or simply to rethink their goals.

As an evolving field, PCS is featured in a wide number of debates that focus on its goals and assessment [Godin and Gingras, 2000; Reynoso, 2001; Burns, O'Connor and Stocklmayer, 2003], particularly when you consider that it aims at the pursuit of a scientific culture within the general public, an issue that is difficult to address and even more to measure when there is not any shared functional definition of scientific culture and any differentiation of the so-called scientific literacy. And, most of all, there is not even agreement on whether the results of PCS should be measured at the level of individuals, or rather of communities [Schauble, Leinhardt and Martin, 1997].

These difficulties go hand in hand with an apparent disparity in the visions and goals of the PCS, which in the first place complicates the debate on their intents and scopes among those who work in this field.

For this reason, a simplified description of PCS events is proposed, in relation to its purposes and recipients, in an attempt to provide a starting point for the discussion of complex issues such as the assessment of the acquisition of knowledge, or the creation of a scientific culture as a result of various PCS approaches [Polino, Fazio and Vaccarezza, 2003].

The different aspects of PCS
In order to encompass all the aspects of science communication, it should be clear that it is necessary to have a measure for its result, informal learning, ${ }^{3}$ which is considered today the 'currency' of PCS activities and media, and for many years now has completely distinguished itself from the type of learning that occurs in formal educational environments. In turn, informal learning has two extremes in a spectrum of results: on the one hand, there is a playful kind of informal learning, which can originate from the involvement of recipients in activities having play and fun as main drivers [Martin, 2001], and on the other hand a meaningful kind of informal learning, which corresponds to the multiple knowledge-building responses of users, when an environment that can potentially facilitate this learning is created.

Going back to the subject of the opportunities offered by PCS and its evaluation, there are four aspects to take into account, in particular two theoretical aspects, and two practical ones. In theoretical terms, the bigger picture requires to consider firstly the above-mentioned informal learning achievements, ranging from playful to meaningful learning. But also, on the theoretical side, it is necessary to have a line that describes the perception we have of the audiences (masses to individuals).

Conversely, the practical aspects refer to the differentiation of the objectives pursued, i.e. the general reasons why science communication is done, which can be described as knowing that science exists, feeling that science is attractive, understanding that it is interesting, or being aware that science is part of one's identity.

\footnotetext{
${ }^{3}$ It is a form of personal and idiosyncratic contextual learning, which depends on individual interests and motivations Sánchez Mora [2011].
} 
Figure 1 shows the axis of the effects and axis of the audiences, as well as the goals deriving from their interactions, the above-mentioned third aspect.

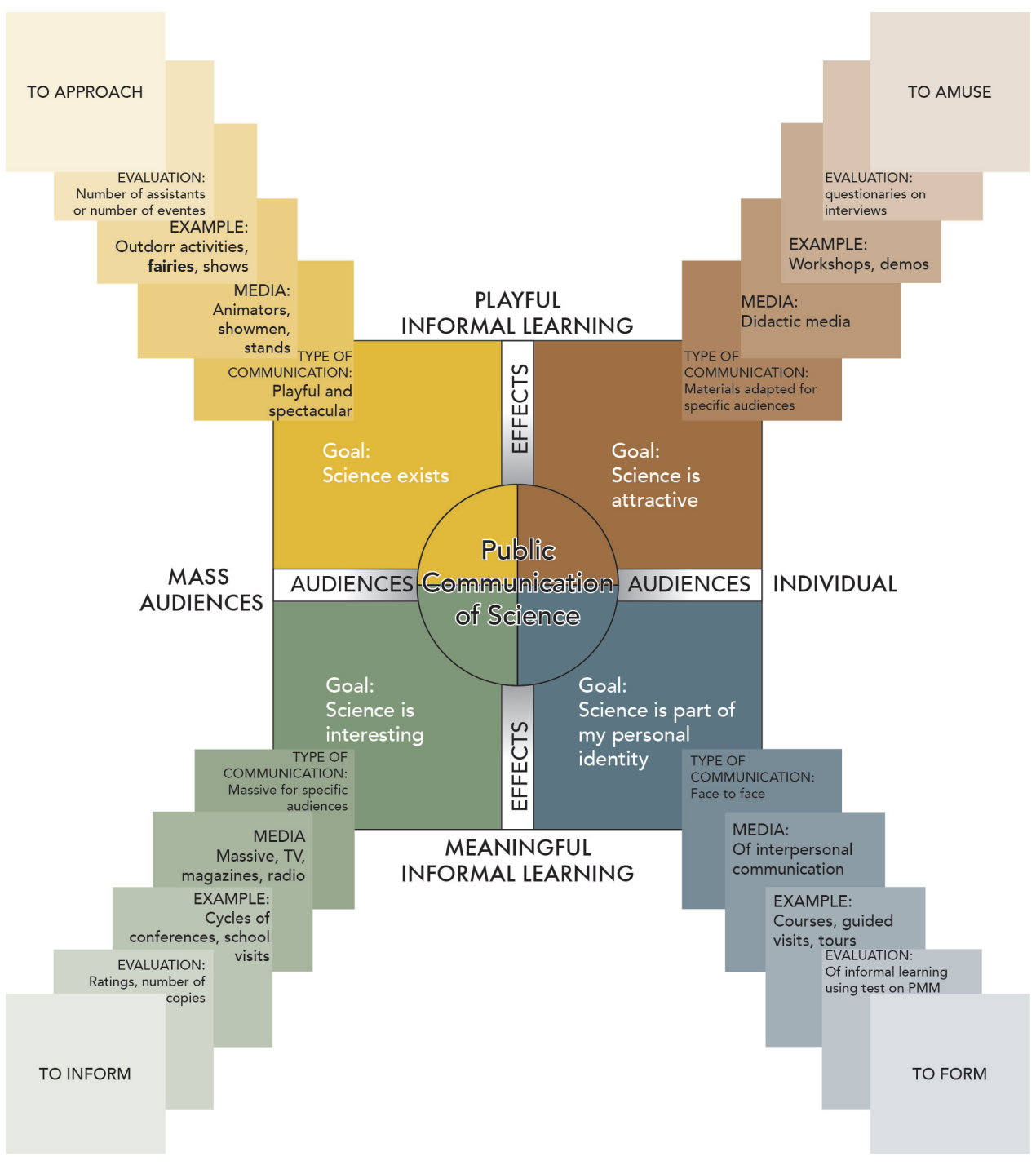

Figure 1. Components of the PSC field, its goals, media and results.

Finally, it is important to consider the application of the three areas above, which translates into how to communicate science, represented in the figure by the tables captioned "communication type".

This fourth aspect, which depends on the previous three, concerns the number of activities and media used to achieved the goals pursued by PCS; in other words, the events or activities and the plan used to reach the goals following the principles outlined above, which are represented in Figure 1 by the series of squares projecting from each quadrant.

\section{Line of the effects}

A debate has long focused on whether PCS should seek entertainment or education as a goal [Rennie, 2001]. As already mentioned, this aspect can be described as a 
spectrum between two informal learning extremes, i.e. from playful to meaningful. The important thing is that any position along the line of effects, expressly or impliedly, determine how a medium doing communication of science defines what is conveyed and in what form.

Although the lines of the effects and of the audiences might seem independent at first glance, they are actually very interconnected. Importantly, what is communicated will vary greatly with the position taken along the axes; with playful informal learning, the aim will be to attract large audiences through arts, cultural and entertainment events that use science and technology as a pretext, whereas meaningful informal learning will require to personally attend to each user based on their needs, motivations and prior knowledge.

\section{Line of the audiences}

As with the effects of PCS, audiences can also be arranged along a spectrum with two contrasting positions at the extremes. At one end there are mass audiences, undefined or heterogeneous, and at the other end there are the recipients considered in their individuality.

Similarly to the effects, the concept you have of the audience will determine the PCS medium's focus of attention at each event. Accepting that the public is massive will require a focus on events for numerous and diverse groups; conversely, assuming that what matters is the individual, then you will have to take into account the various methods existing to adapt each PSC medium's discourse to each individual.

\section{The juxtaposition of the two lines}

The two spectrums (audiences and effects) can be juxtaposed, thus creating four quadrants, each of which describes a specific goal of PCS implemented by the medium that is most suitable to achieve it. In turn, each pair of goals has a common position regarding the effects of a certain medium, i.e. the goals 'science is interesting' and 'science is part of my personal identity' share 'meaningful informal learning' as a result. On the other hand, the goals 'science exists' and 'science is attractive' share the effect that PCS activities generate playful informal learning, but have opposite views of recipients, masses in the first instance and individuals in the second.

Instead, the goals 'science exists' and 'science is interesting' share a massive view of the audiences, but have a different stance on the results: in the first case the goal is the playful informal learning, and in the second it is the meaningful informal learning. Finally, the goal 'science is attractive' and 'science is part of my identity' have a similar position in that they see the audience in their individuality, but they aim at different PCS results: playful informal learning in the first case and meaning informal learning in the second.

\section{The playful informal learning-mass audience quadrant}

In many situations, the primary function of PCS has focused on mass events. In this case, an institution or group usually organises an activity open to all types of 
audience, because what is sought is a first approach to science. There, the challenge for the communicator is how to address the audience and how to leverage science for recreational activities.

In such a case, PCS activities have a show format, and the events organised in this quadrant have the function of bringing visitors closer to science, so they are required to have a spectacular nature, with the sole purpose of having attendees learn that science does exist. In other words, science is a pretext for carrying out the activity. Examples of this are mass events such as concerts, fairs and outdoor shows, and - especially in the case of museums -free open visits.

\section{The mass audience-meaningful informal learning quadrant}

The bottom left quadrant represents a PCS position that shares a massive view of the audience, yet implying that the participation will make the audience interested in science and technology. In this quadrant, activities are addressed to layered audiences, taking into account their characteristics as learners, yet of a massive type.

The PCS activities belonging to this quadrant tend to have an educational nature, and when the institutions or groups implementing them organise events, they have an informative nature, pursuing the goal of mass audiences realising that science is interesting.

Examples of PCS activities in this quadrant are the cycles of lectures by communicators or specialists in various subjects, and a typical case of that in science museums is school visits, which - although addressing large groups pursue specific and meaningful learning.

\section{The individual-playful informal learning quadrant}

The upper right quadrant represents a dramatic shift in the orientation of PCS, because when it is focused on the individual, the issue of its evaluation becomes more complicated: it can no longer be measured by large numbers or statistics as in the above-described quadrants, but only through satisfaction surveys.

The activities that correspond to this quadrant are complemented by science workshops and demonstrations, which tend to be very attractive to users while seeking to create in them an opinion about PCS activities, so that participants can have fun experiencing science-related actions. Workshops and demonstrations that are usually very common in science fairs (where entertainment is used to address particular and specific audiences) are a very good example of this modality.

\section{The individual-meaningful informal learning quadrant}

Finally, this quadrant represents PCS seen as an interpersonal activity aimed at channelling people towards science or literacy [Polino, Fazio and Vaccarezza, 2003]. in which it is necessary to know the characteristics of each individual and their contexts, in order to ensure that they perceive science as part of their identity [Falk, Dierking and Foutz, 2007]. 
In this case the activities can have varied formats, although they are often accompanied by human mediation able to adapt the discourse of the exhibition to the individuality of visitors.

Examples worth mentioning are the courses on scientific issues addressed to non-specialist audiences and, above all, guided visits to science museums, where mediators bring scientific discourse closer to the individual needs for involvement with the theme of each visitor.

PCS methods for each quadrant and their evaluation
A view of the audiences and one of the communication achievements are essential, yet not sufficient to outline the different functions of PCS in the various media. It is necessary to have a plan in order to implement this communication according to the contents of each quadrant.

1. Science communication in the mass audience-playful informal learning quadrant.

In this quadrant, the challenge in terms of communication is how to structure the event to meet the goal of bringing visitors closer to science in an uncomplicated way. The evaluation of it will be on the basis of the number of events held and the attendance level. Which means you can base your evaluation on the number of mass events held over a period of time, or on the dimension of the audience in attendance.

2. Science communication in the mass audience-meaningful informal learning quadrant.

Also in this quadrant, the challenge is addressing mass audiences, but in this case the aim is to show that science is interesting based on the information provided by the media. Therefore, it is necessary to plan PCS activities with meaningful informal learning objectives, i.e. so that they make sense and relate to the daily life of visitors. Here, the evaluation shall have to be based on the number of attendees to lectures, or the circulation and ratings of mass media, or the number of visitors to an exhibition, their attendance time, the recording of their paths, or post-visit evaluations in the case of school visits to a science museum.

3. Science communication in the individual-playful informal learning quadrant. In this case the aim is to entertain the audience through playful activities.

Also, the evaluation may be carried out using memory questionnaires exploring how rewarding the PCS experience was. For example, if a workshop for children aged 10 to 12 is organised, you may ask them to write down their impressions on the activity they participated in, or you can investigate the concepts acquired as a result of the activity through the so-called Personal Meaning Mapping (PMM) [Falk, Moussouri and Coulson, 1998]. In particular, the effects of the workshops or demonstrations can be evaluated through this type of instruments, as they generate information in a fast way.

4. Science communication in the individual-meaningful learning quadrant. In the last quadrant the aim is to have individuals live experiences stimulating meaningful informal learning according to their interests, motivations and knowledge, so that they keep participating in PCS to turn 
science into part of their identity. The goal here is to channel individuals towards science, either vocationally or as part of their culture. In this case the evaluation is done through questionnaires, personal interviews, focus groups or group discussions, according to the type of intervention used. It should be remembered that in this case interpersonal or face-to-face communication activities are implemented.

It is worth mentioning that many of the evaluations carried out at science museums and centres are usually performed only in the playful informal learning / mass audience quadrants and are based on demographic records or statistical data; or in the individual / meaningful informal learning quadrant, in which most of the educational research in museums has been carried out.

\section{Conclusion}

This brief summary is intended to provide an overview of the different categories of objectives and purposes of PCS. In order to translate such objectives into practice, they should provide a basis to develop an array of PCS methods so that they are consistent with specific combinations of audiences and desired effects.

This emphasises the contrast between the merely massive and playful approaches and those that pursue a meaningful informal learning and identity, as postulated by the NSC. ${ }^{4}$

The theoretical differences as to the approaches in each quadrant stem from the different ways to consider how the recipients react in each case. However, the way PCS is defined in terms of objectives and purposes will always depend on the position science communicators take within the quadrants, which will determine the form this type of work is studied, investigated or evaluated.

\section{Translated by Massimo Caregnato}

\section{References}

Burns, T. W., O'Connor, D. J. and Stocklmayer, S. M. (2003). 'Science communication: a contemporary definition'. Public Understanding of Science 12 (2), pp. 183-202. DOI: 10.1177/09636625030122004.

Falk, J. H., Moussouri, T. and Coulson, D. (1998). 'The Effect of Visitors' Agendas on Museum Learning'. Curator: The Museum Journal 412, pp. 107-120. DOI: 10.1111/j.2151-6952.1998.tb00822.x.

Falk, J. H., Dierking, L. D. and Foutz, S., eds. (2007). In Principle, in Practice: Museums as Learning Institutions. U.S.A.: Altamira Press.

Godin, B. and Gingras, Y. (2000). 'What is scientific and technological culture and how is it measured? A multidimensional model'. Public Understanding of Science 9 (1), pp. 43-58. DOI: 10.1088/0963-6625/9/1/303.

\footnotetext{
${ }^{4}$ The results of informal science education proposed in the document produced by the National Science Council represent a broad vision of how popularisers and experts characterise and measure the effects of informal learning experiences. The six strands that they put forward to measure them cover a wide range of approaches, from those aimed at cognitive and conceptual change to those more related to participation or identity [Rodari, 2009].
} 
Martin, L. (2001). 'Free-Choice Science Learning: Future directions for researchers'. In: Free Choice Science Education: how we learn science outside school. Part III, Chapter 12. Ed. by J. H. Falk. New York, U.S.A.: Teachers College Press, pp. 186-198.

Polino, C., Fazio, M. E. and Vaccarezza, L. (2003). ‘Medir la percepción pública de la ciencia en los países iberoamericanos. Aproximación a problemas conceptuales'. Revista Iberoamericana de ciencia, Tecnología, Sociedad e Innovación 5. URL: http://www. oei.es/revistactsi/numero5/articulo1.htm.

Rennie, L. J. (2001). 'Communicating Science through interactive science centres: a research perspective'. In: Science Communication in Theory and Practice. Ed. by S. M. Stocklmayer, M. M. Gore and C. Bryant. Boston, Science and Technology Library: Kluwer Academic Publishers, pp. 107-121.

Reynoso, E. (2001). La evaluación de la divulgación de la ciencia. Paper presented at the round table of the same name at the $X$ National Congress of Public Communication of Science. Toluca, Edo. de México, México.

Rodari, P. (2009). 'Learning science in informal environments: people, places and pursuits. A review by the US National Science Council'. Review. JCOM 8 (3), R02.

Sánchez Mora, C. (2011). ‘Los museos y la cultura científica: una aproximación a través del recuerdo de las exhibiciones museográficas'. Revista Museología e Patrimonio 4 (1). Published on 6 January 2012, pp. 3-27. URL: http: //revistamu seologiaepatrimonio.mast.br/index.php/ppgpmus/article/view/137.

Schauble, L., Leinhardt, G. and Martin, L. (1997). 'A Framework for Organizing a Cumulative Research Agenda in Informal Learning Contexts'. The Journal of Museum Education 22 (2-3), pp. 3-8.

Vaccarezza, L. S. (2009). 'Estudios de cultura científica en América Latina'. Redes 15 (30), pp. 75-103. URL:

http://redalyc.org. www.redalyc.org/articulo. oa?id=90721335004.

Author

\section{How to cite}

María del Carmen Sánchez Mora is a biologist at the Faculty of Sciences of UNAM, having obtained a Master's Degree in Ecology and Human Biology from the University of Stanford, California, and a Ph.D. in biology teaching from UNAM. Her field of work is science popularisation through museum exhibitions and investigation in non-formal and informal education, in which domain she has trained many people in Mexico and abroad. She was part of the original team of the Centro Universitario de Comunicación de la Ciencia, now Dirección General de Divulgación de la Ciencia of UNAM. E-mail: masanche@dgdc.unam.mx.

del Carmen Sánchez-Mora, M. (2016). 'Towards a taxonomy for public communication of science activities'. JCOM 15 (02), Y01_en. 